\title{
Life-threatening bleeding under vitamin $K$ antagonists in spite of an INR in the therapeutic range
}

\author{
Mathilde Gavillet $\cdot$ Claire Abbal $\cdot$ Sabine Schmidt . \\ Jasmine Nötzli · Jean-François Lambert • \\ Anne Angelillo-Scherrer
}

Published online: 18 March 2011

(C) Springer Science+Business Media, LLC 2011

Keywords Oral anticoagulation - Factor IX · Propeptide mutation - Vitamin K antagonists - Prosthetic heart valve

The major risk associated with the use of vitamin $\mathrm{K}$ antagonists (VKA) is haemorrhage, which might be severe or even life-threatening. In clinical studies where anticoagulation intensity was carefully monitored, treatment with VKA increases the risk of major bleeding by $0.3-0.5 \%$ per year when compared to controls [1]. In randomized trials including patients with mechanical heart valves, VKA treatment was associated with a risk of major bleeding ranging between 1 and $8.3 \%$ [1]. However, in clinical practice, the rates are less consistent [1]. The major determinants of VKA-induced bleeding are the intensity of the anticoagulant effect, the patient characteristics, the concomitant use of drugs that interfere with hemostasis, and the length of therapy [1].

Here, we report a case of a rare hypersensitivity to VKA due to a mutation of factor IX (FIX) propeptide in the context of a prosthetic mechanical heart valve.

In November, 2008, a 62-year-old man presented with an obstructive laryngeal hematoma (Fig. 1a, b) after tongue biting requiring intratracheal intubation. His medical history

\footnotetext{
M. Gavillet · C. Abbal · J. Nötzli · J.-F. Lambert ·

A. Angelillo-Scherrer $(\square)$

Service and Central Laboratory of Hematology, Centre Hospitalier Universitaire Vaudois and University of Lausanne, rue du Bugnon 46, CH-1011 Lausanne, Switzerland e-mail: Anne.Angelillo-Scherrer@chuv.ch

\section{S. Schmidt}

Department of Radiology, Centre Hospitalier Universitaire Vaudois and University of Lausanne, rue du Bugnon 46, CH-1011 Lausanne, Switzerland
}

revealed prosthetic mechanical aortic valve replacement in July 2008 (Bentall procedure, Cardiomedic prosthesis). Oral anticoagulation with VKA (acenocoumarol) was initiated post-operatively. When the laryngeal hematoma appeared, the patient's International Normalized Ratio (INR) was 3.5. In December, 2008, the patient was admitted to the intensive care unit with a massive hemothorax (Fig. 1c) occurring 10 days after a reintervention to cure a paraprosthetic leak, and requiring surgical drainage. INR was 1.3. The patient's and his relatives reported no history of bleeding. Aspirin, the only patient's medication favoring bleeding, had been stopped 4 days before the first bleeding episode. Before the introduction of acenocoumarol, blood count, prothrombin time (PT) and activated partial thromboplastin time (APTT) were within the normal range.

Coagulation tests are listed in Fig. 1d. Both major bleeding episodes were accompanied by INR values within or even below the therapeutic range (therapeutic range for a mechanical valve carrier: 2.5-3.5) [2]. However, APTT was abnormally prolonged because FIX was exaggeratedly lower than the other vitamin $\mathrm{K}$ dependant factors (II, VII, $\mathrm{X})$. Factor V, VIII, XI and XII were within the normal range during both bleeding episodes. APTT and FIX both normalized after vitamin $\mathrm{K}$ supplementation and bleeding did not recur.

Genomic DNA was purified from the patient whole blood, and FIX exon 2 was amplified using the forward primer $5^{\prime}$-catgcctaaagagaaattggct- $3^{\prime}$ and the reverse primer $5^{\prime}$-tgcatctgaagggtattatgtgg- $3^{\prime}$. The thermocycling conditions of the PCR were $30 \mathrm{~s} 94^{\circ} \mathrm{C}, 1 \mathrm{~min} 53^{\circ} \mathrm{C}$, and $1 \mathrm{~min}$ $72^{\circ} \mathrm{C}$, for 40 cycles. Direct sequencing of the PCR product showed a single guanosine-to-adenosine transition at nucleotide 109 (numbered from genBank accession gi180552) causing the substitution of alanine at locus-10 (Ala-10) by threonine in the FIX propeptide (Fig. 2a). 

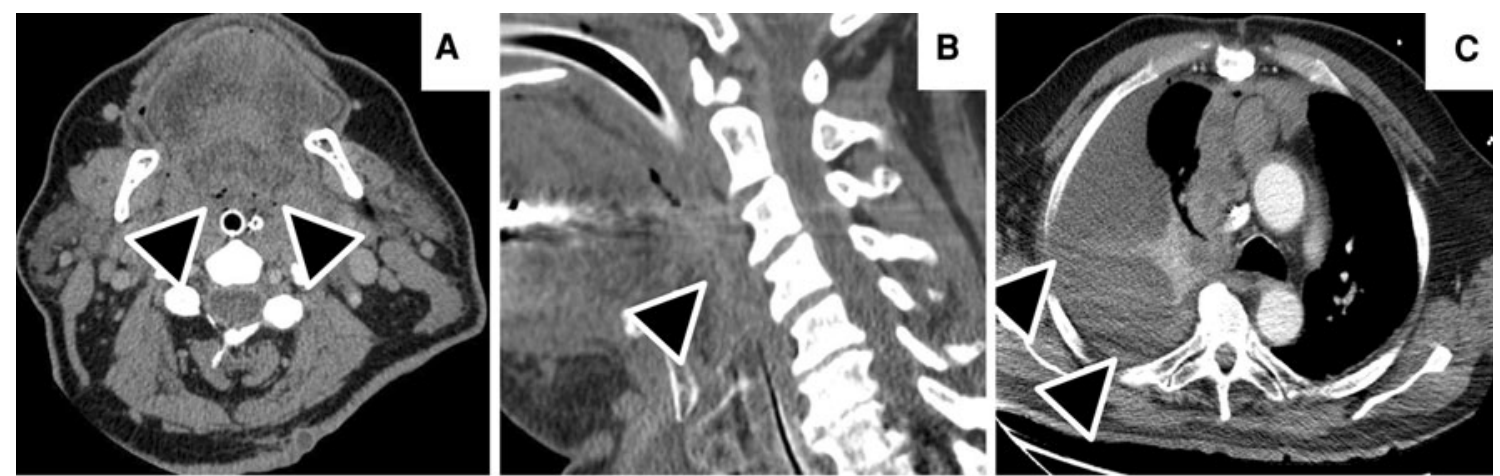

\begin{tabular}{|c|c|c|c|c|c|c|}
\hline $\begin{array}{l}\text { Coagulation test } \\
\text { (unit) }\end{array}$ & $\begin{array}{l}\text { Normal } \\
\text { range }\end{array}$ & $\begin{array}{c}\text { July } 2008 \\
\text { pre-operative } \\
\text { values }\end{array}$ & $\begin{array}{c}\text { November } 2008 \\
1^{\text {st }} \text { bleeding } \\
\text { episode }\end{array}$ & $\begin{array}{c}\text { After vitamin K } \\
\text { supplementation }\end{array}$ & $\begin{array}{l}\text { December } 2008 \\
2^{\text {nd }} \text { bleeding } \\
\text { episode }\end{array}$ & $\begin{array}{c}\text { December } 2008 \\
\text { Immediately } \\
\text { before } \\
\text { discharge }\end{array}$ \\
\hline INR & 1 & 1.0 & 3.5 & 1.1 & 1.3 & 1.0 \\
\hline APTT (sec.) & $20-30 \mathrm{sec}$ & 29 & 142 & 38 & 49 & 22 \\
\hline Fibrinogen ( $g / l)$ & $2.0-4.0 \mathrm{~g} / 1$ & & 4.4 & & 7.5 & \\
\hline Factor VII (\%) & $70-120 \%$ & & 11 & & 65 & \\
\hline Factor II (\%) & $70-120 \%$ & & 20 & & 75 & \\
\hline Factor X (\%) & $70-120 \%$ & & 11 & & 39 & \\
\hline Factor IX (\%) & $70-120 \%$ & & 1 & 80 & 10 & \\
\hline Factor V (\%) & $70-120 \%$ & & 145 & & 175 & \\
\hline Factor VIII (\%) & $70-120 \%$ & & 185 & & 245 & \\
\hline Factor XI (\%) & $70-120 \%$ & & 110 & & 95 & \\
\hline Factor XII (\%) & $70-120 \%$ & & 110 & & 67 & \\
\hline
\end{tabular}

INR, international normalized ratio; APTT, activated partial thromboplastin time.

Fig. 1 a (axial) and $\mathbf{b}$ (sagittal) CT of the neck, showing an obstructive laryngeal hematoma (arrow heads). $\mathbf{c}$ CT of the chest showing a right hemothorax (arrow heads). d Table including coagulation tests

Fig. 2 a Schematic

representations of, upper line, FIX gene (accession number M11309), and, lower line, FIX propeptide. The mutation is indicated by an arrow line [6]. Exons are numbered.

$G$ guanosine, $A$ adenosine, $G L A$ Vitamin K-dependent carboxylation/gammacarboxyglutamic domain, EGF Epidermal growth factor-like domain, $B$ family pedigree. Affected males in black, female carriers in stripes, wild type phenotype in white, unknown phenotype in grey, deducted phenotypes circled with grey. Arrow head indicates the index patient
A
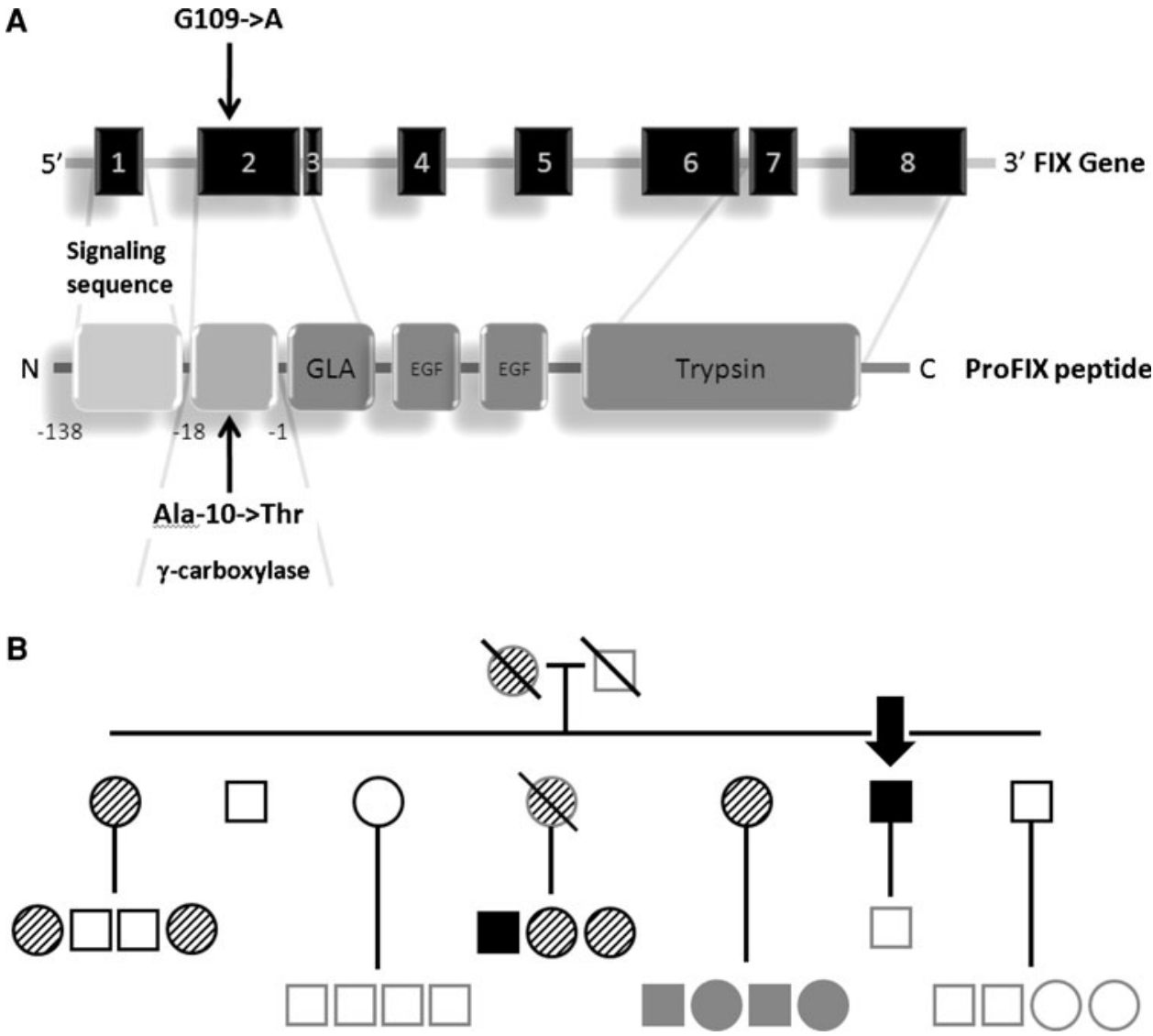


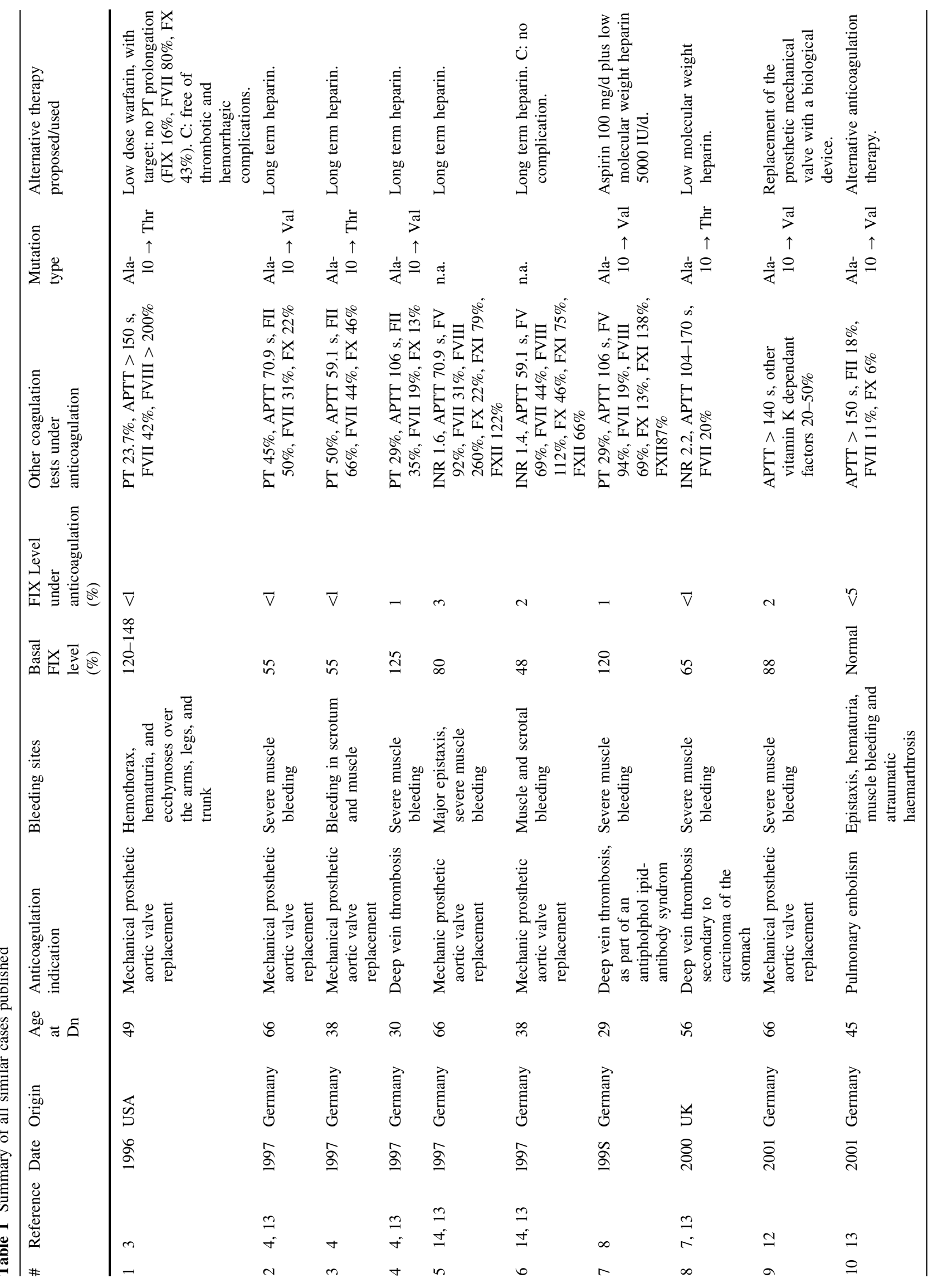




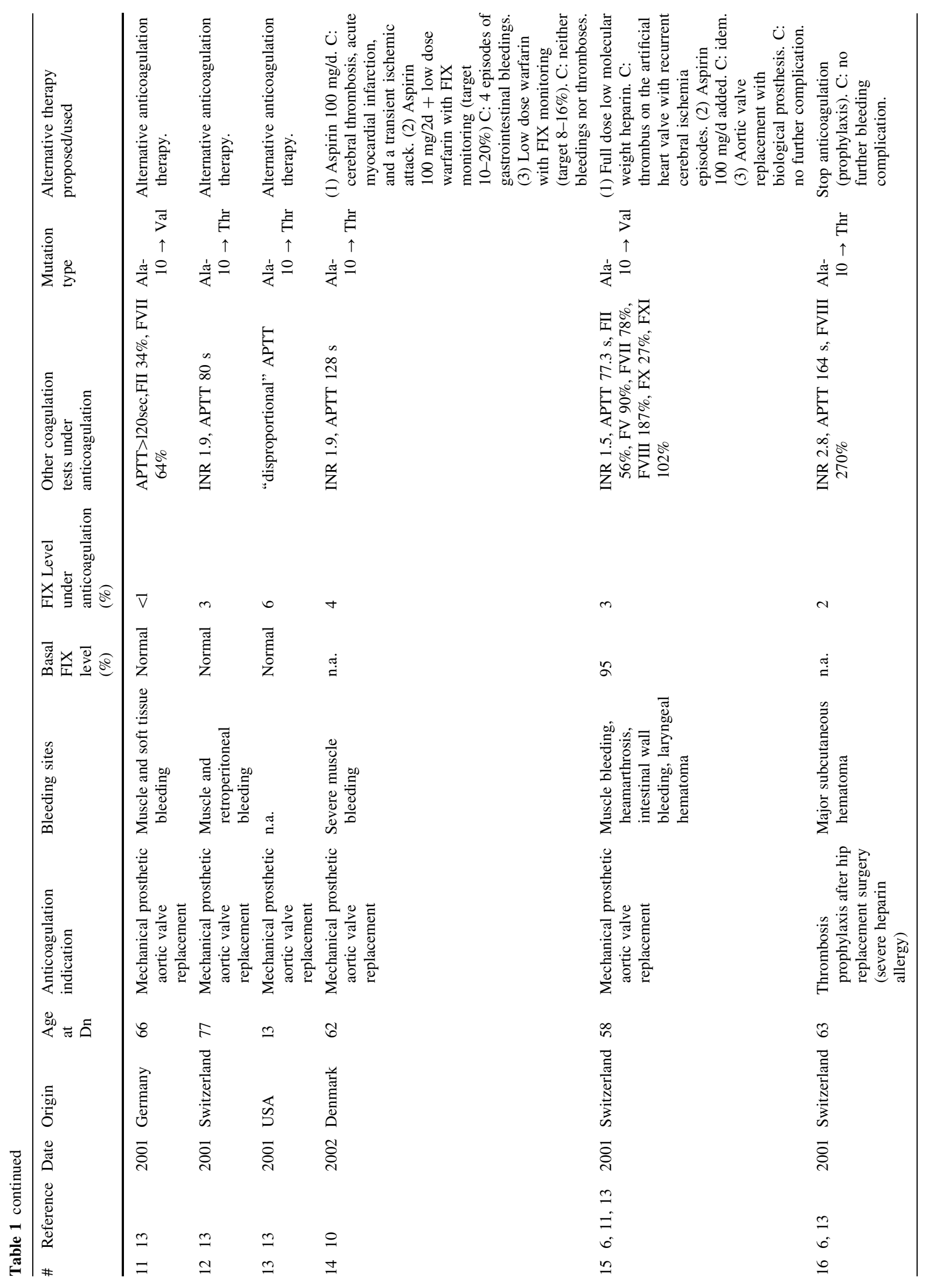




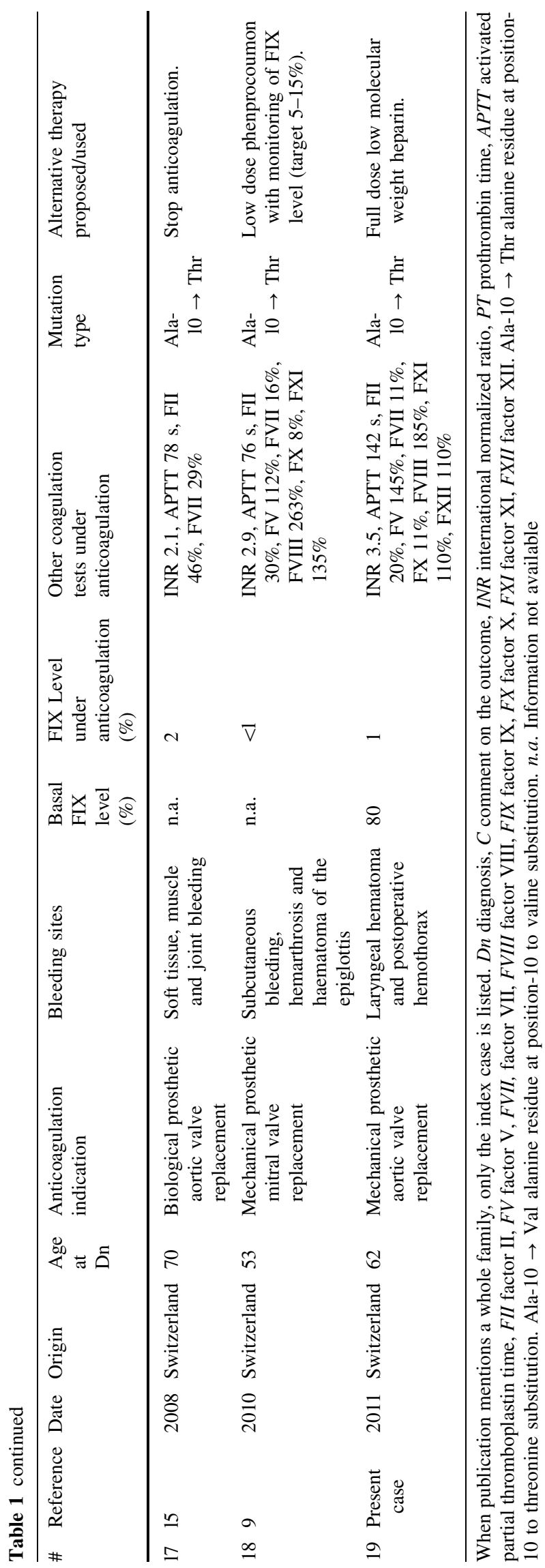

Screening of patient's relatives allowed to identify seven further asymptomatic carriers (two males, five females) (Fig. 2b).

Because of the severe bleeding complications presented by our patient, the oral anticoagulation was replaced by low molecular weight heparin at therapeutic dose monitored by anti-Xa activity in order to be sure that anti-Xa activity levels were maintained within the therapeutic range. 15 months later no recurrence of bleeding nor thrombotic complication were observed.

In the literature, two point mutations causing Ala-10 substitution by either a valine (Ala-10Val) or a threonine (Ala-10Thr) have been described [3, 4]. Ala-10 is located at the essential recognition site for the $\gamma$-carboxylase [5] and is highly conserved in all vitamin K-dependent coagulation factors [6]. Ala-10Val and Ala-10Thr FIX variants display a more than 30 -fold lower affinity for the $\gamma$-carboxylase than the wild type propeptide [3]. The affinity of the mutated enzymatic peptide complex for reduced vita$\min \mathrm{K}$ is decreased when compared to the enzymatic complex comprising the wild type peptide [3]. Consistantly, the $\gamma$-carboxylation of these FIX variants is less efficient and becomes dramatically impaired in patients with VKA medication [3].

Male patients have a normal or slightly lowered basal FIX level. However, under VKA therapy, they display a dramatic decrease of FIX activity that is out of proportion with the other vitamin $\mathrm{K}$ dependant coagulation factors (II, VII, X). APTT is thus abnormally prolonged, while PT and INR remain within, or even below, the therapeutic range; and patients exibit severe and sometimes lifethreatening soft tissue and muscle bleeding [3, 4, 7-16]. From time to time misdiagnosed for mild hemophilia B, patients carrying a FIX propeptide mutation can be distinguished by an absence of self or family bleeding history as well as normalization of APTT and FIX level after vitamin $\mathrm{K}$ administration. Because FIX gene is located on chromosome $\mathrm{X}$, males are more affected than females. One female patient carrier of the Ala-10Val mutation was treated by VKA [17]. When INR was 2.3, FIX level was $16 \%$. This patient did not develop bleeding complications [17].

So far 18 similar cases have been reported in the literature worldwide [3, 4, 7-16] (Table 1). Systematic screening in 4039 individuals yielded no further case [4, 18-20]. Therefore, prevalence of Ala-10Thr or Ala-10Val variants in the population is estimated to range from $1 / 1,000$ to $1 / 10,000$ and systematic screening prior to initiating oral anticoagulation is not indicated. However it is worth noticing that about one-third of these patients (6/19) originate from Switzerland including our current reported case. Although selection bias is possible, one study using haplotype analysis revealed a founder effect in the five German 
and Swiss patients carrying a FIX variant (1 Ala-10Val and and 4 Ala-10Thr) derived from a common founder [14]. We postulate that the prevalence of this genetic variant may be higher in the Swiss population. APTT screening is certainly of interest in any bleeding patient with INR values within the therapeutic range, especially in male patients. If abnormally prolonged, quantitative determination of FIX level can lead to the diagnosis. Further use of VKA is not recommended. For the present being, low molecular weight heparins represent an inconvenient but safe alternative. An alternative could be to monitor FIX activity targeting a level of $5-15 \%$, as previously described $[3,10,11]$. We did not choose this therapeutic option for our patient as he presented a severe bleeding episode with a FIX level at $10 \%$ (Fig. 1d). The replacement of the prosthetic mechanical valve by a biological graft in order to avoid anticoagulation was discussed but the risk of morbidity and mortality associated with cardiac surgery was considered to be too high. In the future, patients with FIX propeptide mutation may benefit from the novel oral anti-thrombin and anti-Xa inhibitors, yet further validation studies are needed.

Acknowledgments We thank Drs. M. Wicki, B. Portmann and Zimerli for participating in the screening part of the study.

\section{References}

1. Schulman S, Beyth RJ, Kearon C, Levine MN (2008) Hemorrhagic complications of anticoagulant and thrombolytic treatment: American college of chest physicians evidence-based clinical practice guidelines (8th Edition). Chest 133 (6 Suppl): 257S-298S. doi:10.1378/chest.08-0674

2. Salem DN, O'Gara PT, Madias C, Pauker SG (2008) Valvular and structural heart disease: American college of chest physicians evidence-based clinical practice guidelines (8th Edition). Chest 133(6 Suppl):593S-629S. doi:10.1378/chest.08-0724

3. Chu K, Wu SM, Stanley T, Stafford DW, High KA (1996) A mutation in the propeptide of factor IX leads to warfarin sensitivity by a novel mechanism. J Clin Invest 98(7):1619-1625. doi:10.1172/JCI118956

4. Oldenburg J, Quenzel EM, Harbrecht U, Fregin A, Kress W, Muller CR, Hertfelder HJ, Schwaab R, Brackmann HH, Hanfland $P$ (1997) Missense mutations at ALA-10 in the factor IX propeptide: an insignificant variant in normal life but a decisive cause of bleeding during oral anticoagulant therapy. $\mathrm{Br} \mathrm{J}$ Haematol 98(1):240-244

5. Jorgensen MJ, Cantor AB, Furie BC, Brown CL, Shoemaker CB, Furie B (1987) Recognition site directing vitamin K-dependent gamma-carboxylation resides on the propeptide of factor IX. Cell 48(2):185-191. doi:0092-8674(87)90422-3[pii]
6. Furie B, Furie BC (1988) The molecular basis of blood coagulation. Cell 53(4):505-518

7. Aegerter C, Fontana S, Fux C, Demarmels Biasiutti F (2003) Life threatening bleeding under adequate oral anticoagulation. Cases 4a, b. Hamostaseologie 23(3):113-116. doi:10.1267/Hamo03030 11303030113

8. Baker P, Clarke K, Giangrande P, Keeling D (2000) Ala-10 mutations in the factor IX propeptide and haemorrhage in a patient treated with warfarin. Br J Haematol 108(3):663

9. Harbrecht U, Oldenburg J, Klein P, Weber D, Rockstroh J, Hanfland P (1998) Increased sensitivity of factor IX to phenprocoumon as a cause of bleeding in a patient with antiphospholipid antibody associated thrombosis. J Intern Med 243(1):73-77

10. Holbro A, Marbet GA, Tran TH, Oldenburg J, Friesewinkel O, Tsakiris DA (2010) Prosthetic heart valves and rare hypersensitivity to vitamin $\mathrm{K}$ antagonists resulting from factor IX mutation: how to manage anticoagulation? Haemophilia 16(1):187-189. doi:10.1111/j.1365-2516.2009.02115.x

11. Kristensen SR (2002) Warfarin treatment of a patient with coagulation factor IX propeptide mutation causing warfarin hypersensitivity. Blood 100(7):2676-2677

12. Lammle B (2003) Clinical problems with oral anticoagulation-3 case reports. Ther Umsch 60(1):63-66

13. Neuhaus T, Hertfelder HJ, Hess L, Oldenburg J, Walger P, Vetter $H$ (2001) An uncommon cause of severe soft tissue bleeding during phenprocoumon treatment. Dtsch Med Wochenschr 126(25-26):754-756. doi:10.1055/s-2001-15099

14. Oldenburg J, Kriz K, Wuillemin WA, Maly FE, von Felten A, Siegemund A, Keeling DM, Baker P, Chu K, Konkle BA, Lammle B, Albert T (2001) Genetic predisposition to bleeding during oral anticoagulant therapy: evidence for common founder mutations (FIXVal-10 and FIXThr-10) and an independent CpG hotspot mutation (FIXThr-10). Thromb Haemost 85(3):454-457

15. Quenzel EM, Hertfelder HJ, Oldenburg J (1997) Severe bleeding in two patients due to increased sensitivity of factor IX activity to phenprocoumon therapy. Ann Hematol 74(6):265-268

16. Ulrich S, Brand B, Speich R, Oldenburg J, Asmis L (2008) Congenital hypersensitivity to vitamin $\mathrm{K}$ antagonists due to FIX propeptide mutation at locus -10: a (not so) rare cause of bleeding under oral anticoagulant therapy in Switzerland. Swiss Med Wkly 138(7-8):100-107

17. Bestmann L, Zuger M, Oldenburg J, Buhler D, Maly FE (2001) Coagulation factor IX propeptide mutations causing coumarin hypersensitivity: identification of female alanine- 10 valine heterozygotes. Thromb Haemost 85(3):567-568

18. Peters J, Luddington R, Brown K, Baglin C, Baglin T (1997) Should patients starting anticoagulant therapy be screened for missense mutations at Ala-10 in the factor IX propeptide? $\mathrm{Br} \mathbf{J}$ Haematol 99(2):467-468

19. Tassies D, Monteagudo J, Maragall S, Ordinas A, Reverter JC (2005) No impact of factor IX Ala-10 mutations in acenocoumarol-treated southern Europeans. Blood Coagul Fibrinolysis 16(8):563-566

20. van der Meer FJ, Vos HL, Rosendaal FR (1999) No indication for APTT screening in patients on oral anticoagulant therapy. Thromb Haemost 81(3):364-366 